\title{
EFFECT OF LACTOBACILLUS POSTBIOTICS ON ENTAMOEBA HISTOLYTICA TROPHOZOITES
}

\author{
Fabiola l. Cuellar-Guevara, María P. Barrón-González*, and Jorge L. Menchaca-Arredondo
}

Department of Cell Biology and Genetics, Faculty of Biological Sciences, Universidad Autónoma de Nuevo León, Nuevo León, México

\begin{abstract}
\end{abstract}
Background: Amebiasis is an infectious disease caused by Entamoeba histolytica. It represents one of the three worldwide leading causes of death by parasites and a public health problem due to its frequency, morbidity, mortality, and easy dispersion. Objective: The study was aimed to evaluate the in vitro effect of Lactobacillus spp. postbiotics on E. histolytica trophozoites (HM1-IMSS strain) and to determine morphometric changes in trophozoite membrane by atomic force microscopy $\overline{\underline{\alpha}}(\mathrm{AFM})$. Methods: Bioassays on trophozoites were conducted with lyophilized postbiotics at $0.1,0.3$, and $0.5 \mathrm{mg} / \mathrm{mL}$ concentrations, and trophozoite samples were obtained for AFM analysis. Results: Results indicated postbiotic inhibitory activity; the highest percentage inhibition was $89.63 \%$ at $0.5 \mathrm{mg} / \mathrm{mL}$. Trophozoites nanomechanical analysis showed $28.32 \%$ increase in ruggedness and $56 \%$ decrease in size with treatments compared to the control. Conclusion: Our study showed that the synergy of $L a c t o-$ bacillus postbiotics inhibited $E$. histolytica HM1-IMSS in vitro growth under axenic conditions, inducing morphometric alterations in trophozoites' cell membrane. These results would allow designing strategies or treatments aimed at E. histolytica control in the future. (REV INVEST CLIN. 2019;71:402-7)

Key words: Protozoa. Amoebiasis. Probiotic. Metabolites. Antimicrobial. Atomic force microscopy.

\section{INTRODUCTION}

Amebiasis is an infection that may have or not clinical manifestations; $90 \%$ of amebic infections are asymptomatic and self-limiting (estimated, 50 million cases per year). Only $10 \%$ of infected persons develop an acute intestinal or extraintestinal disease ${ }^{1}$. According to the World Health Organization (WHO), Entamoeba histolytica is the third leading parasitic cause of death $(100,000 \text { deaths/year })^{2}$, and after nalaria, amebiasis is the second most lethal disease-caused by a protozoan parasite. This infection has a worldwide distribution, with a higher incidence in dêveloping countries and high prevalence in countries with poor sanitary and socioeconomic conditions 3 . The risk groups include male homosexuals, travelers and
*Corresponding author:

María P. Barrón-González

E-mail: maria.barrongn@uanl.edu.mx
Received for publication: 07-06-2019

Approved for publication: 23-07-2019

DOI: 10.24875/RIC.19003134 
recent immigrants, and institutionalized populations ${ }^{4}$. Food and water contamination combined with a poor hygiene are the main sources of transmission. Waterassociated outbreaks of $E$. histolytica disease as well as sexually transmitted infections have been report$\mathrm{ed}^{5}$. Metronidazole is the first-line drug for the treatment of invasive amebiasis, although it has undesirable side effects (nausea, headache, and among other adverse manifestations) and is potentially carcinogenic 6 . Unfortunately, E. histolytica, as many other parasites, has developed mechanisms to evade the drug pressure ${ }^{7}$ and became resistant ${ }^{8,9}$. Due to the medical importance of $E$. histolytica, it is necessary to search for alternative compounds that inhibit this parasite. Investigations have been conducted with probiotic bacteria to find therapeutic alternatives for amebiasis. Prebiotics, probiotics, and synbiotics are appealing as preventive and therapeutic agents for human medical disorders. Their efficacy depends on disease etiology and the probiotic strain used ${ }^{10}$. Probiotics are living microorganisms that confer health benefits to the host when administered in adequate amounts; however, dead bacteria and their components can also exhibit probiotic properties ${ }^{11}$. Recently, increasing evidence supports the notion that certain probiotic-derived components, such as bacteriocins, lipoteichoic acids, surface layer protein, and secreted protein, have a similar protective role on intestinal barrier function as that of live probiotics. These bioactive components have been named "postbiotics" in the most recent publications ${ }^{12}$. Postbiotics are "soluble factors (products or metabolic byproducts) secreted by live bacteria or released after bacterial lysis," and they provide physiological benefits to the host ${ }^{13,14}$. However, most investigations in this field are focused on infections of bacterial origin and not on those of parasitic origin.

Typical characteristics of E. histolytica are observed by specific stains and the optical, fluorescence, transmission electron, or scanning microscopes have been used to examine this material ${ }^{15}$. However, these cells can be currently analyzed using new microscopic tools such as atomic force microscopy (AFM), which allows to observe structures at a nanometric resolution and analyze physical-mechanical properties to study biological material ${ }^{16}$. In the present study, the in vitro effect of lyophilized postbiotics on E. histolytica trophozoites was determined, and cell membranes were analyzed by AFM to evaluate morphometric changes.

\section{METHODS}

\section{E. histolytica culture medium}

The TYI-S-33 medium for E. histolytica (HM1-IMSS strain) culture and maintenance was prepared àccording to Diamond et al. ${ }^{17}$

\section{Probiotic bacteria culture and obtention of postbiotics}

Lactobacillus plantarum (229 strain) and Lactobacillus casei (CCRC 10697 strain) were cultivated in Man-Rogosa-Sharpe broth (Difco, Becton Dickinson Co., Sparks, MD, USA) and incubated (LabNete for $24-48 \mathrm{~h}$ at $37^{\circ} \mathrm{C}$. After incubation, the extracellular factor supernatant was obtained by centrifugation (IEC $\mathrm{CL}_{30}$ Centrifuge Thermo SCIENTIFIC ${ }^{\oplus}$ ) at $2500 \mathrm{rpm}$ for $20 \mathrm{~min}$. The recovered material was filtered using Millipore container $(0.22 \mu \mathrm{m}$, GP Millipore Express ${ }^{\oplus}$ PLUS Membrane, Massachusetts, USA). Then, $140.26 \mathrm{~g}$ of ammonium sulfate were added to $80 \%$ saturation, stirring during $24 \mathrm{~h}$ at $4^{\circ} \mathrm{C}$ in an ice bath. The mixture was centrifuged at $2547 \mathrm{rpm}$ för $1 \mathrm{~h}$. The obtained protein precipitate was resuspended with $0.2 \mathrm{M}$ phosphate buffer at $\mathrm{pH} 7.2$ and was dialyzed into membranes (spectra/Por membrä̀ tubing). A protein qualitative determination waş made to dialyzed material by Biuret test. The dialyzed material was placed in glass containers $\left(\mathrm{LABCONCO}{ }^{\circledR}\right.$ ) for lyophilization (LABCONCO Corporation, Kansas City, Missouri 63132, USA) at $0.133 \mathrm{mBar}$ pressure and $-40^{\circ} \mathrm{C}$ collector temperature for $12 \mathrm{~h}$.

\section{Bioassay}

The in vitro effect of lyophilized postbiotics ome. histolytica trophozoites was evaluated. E. histelytica trophozoites $\left(2 \times 10^{4} \mathrm{cell} / \mathrm{mL}\right.$ ) were axenically grown in $13 \times 150 \mathrm{~mm}$ borosilicate tubes containing $5 \mathrm{~mL}$ of TYI-S-33 medium and $0.55 \mathrm{~mL}$ of adult bovine serum-antibiotic mixture (400 IU penicillin and $4 \mathrm{mg}$ streptomycin). Different concentrations (0.1, 3,3 , and $0.5 \mathrm{mg} / \mathrm{mL}$ ) of lyophilized postbiotics from each strain were added; $5 \mathrm{~mm}$ coverslips were placeed inside the tubes and incubated for $72 \mathrm{~h}$ at $37^{\circ} \mathrm{C}$. Nisin, at the same concentrations as the postbiotics, and metronidazole $(0.1 \mathrm{mg} / \mathrm{mL})$ were also incubated in separate assays with trophozoites. Each coverslip was removed for AFM analysis. Tubes were chilled in an 
Table 1. Effect of Lactobacillus postbiotics on cell growth of E. histolytica trophozoites after $72 \mathrm{~h}$ incubation

\begin{tabular}{|c|c|c|c|}
\hline Treatment & $\begin{array}{l}\text { Concentration } \\
(\mathrm{mg} / \mathrm{mL})\end{array}$ & $\begin{array}{c}\text { Growth } \\
\left(1 \times 10^{4} \text { cell } / \mathrm{mL}\right)\end{array}$ & $\begin{array}{c}\text { Growth inhibitior } \\
\text { at } 72 \mathrm{~h}\end{array}$ \\
\hline \multirow{3}{*}{$\begin{array}{l}\text { Lactobacillus casei } \\
\text { postbiotics }\end{array}$} & 0.1 & 3.68 & 63.65 \\
\hline & 0.3 & 8.1 & 20 \\
\hline & 0.5 & 4.71 & 53.48 \\
\hline \multirow{3}{*}{$\begin{array}{l}\text { Lactobacillus plantarum } \\
\text { postbiotics }\end{array}$} & 0.1 & 9.01 & 11 \\
\hline & 0.3 & 5.1 & 49.63 \\
\hline & 0.5 & 8.05 & 20.49 \\
\hline \multirow[t]{3}{*}{ Postbiotics synergy } & 0.1 & 6.37 & 37 \\
\hline & 0.3 & 4 & 60.49 \\
\hline & 0.5 & 1.05 & $89.63^{*}$ \\
\hline \multirow[t]{3}{*}{ Nisin } & 0.1 & 2 & 80.25 \\
\hline & 0.3 & 1.7 & 83.21 \\
\hline & 0.5 & 1.05 & 89.63* \\
\hline Metronidazole & 0.1 & 0 & 100 \\
\hline Control & & 10.13 & - \\
\hline
\end{tabular}

a Mean values determined in three independent events done in triplicate.

*The data are highly significant according to the ANOVA and Tukey test.

ANOVA: Analysis of variance.

ice-water bath for $20 \mathrm{~min}$ at $4^{\circ} \mathrm{C}$. The total number of cells per $\mathrm{mL}$ was determined using a hemocytometer (Neubauer chamber, American ${ }^{\circledR}$ ).

\section{Preparation of trophozoite samples and AFM analysis}

The trophozoites adhered to the coverslips surface were fixed with $2.5 \%$ glutaraldehyde tempered at $37^{\circ} \mathrm{C}$ during $30 \mathrm{~min}$. Coverslips were rinsed with deionized water to remove glutaraldehyde excess and placed with double-sided tape on the special sample holder to observe by AFM. An AFM - Ntegra Prima NT-MDT sitting on an active damping table was used to observe the samples employing a silicon nitride (Si3N4) rectangular cantilever (RTESPA-300, tip radius $8 \mathrm{~nm}$ ) with a length of $125 \mu \mathrm{m}$ and nominal spring constant of $40 \mathrm{~N} / \mathrm{m}$. AFM images (height, amplitude, and phase) were obtained under normal conditions while operating the instrument in semi-contact mode (tapping). On the other hand, roughness analysis was performed comparing the obtained images using a cantilever as mentioned above with a nominal resonant frequency of $300 \mathrm{kHz}$. The analysis was carried out using the software package NOVA version 1.1.0.1921 and WSxM v5.0 Develop 8.0.

\section{Statistical analysis}

An analysis of variance test was performed to determine the in vitro effect of postbiotics on E. histolytica trophozoites with $\mathrm{p}<0.05$ using the statistical software package SPSS version 17.0. Tukey multiple comparison test with a significance level of $<5 \%$ was then performed.

\section{RESULTS}

\section{Bioassay}

Table 1 shows the in vitro effect of postbiotiç्ड on $E$. histolytica trophozoites. The lyophilized postbiotics showed variable percentages of inhibition for each strain evaluated independently. The percentage inhibition of postbiotics synergy at a concentration of 0.5 $\mathrm{mg} / \mathrm{mL}$ was significantly higher than the cont similar to metronidazole and was the same as Nisin. Significant difference between treatments was found.

\section{AFM analysis}

We analyzed the in situ cell morphology of E. histolytica trophozoites using tapping mode (Fig. 1). The 
Figure 1. E. histolytica images by atomic force microscopy. (A) Control trophozoite: the cell membrane's porosity and pleomorphic structure can be appreciated. (B) Trophozoites' size decreased with postbiotics synergy treatment at $0.5 \mathrm{mg} / \mathrm{mL}$ concentration.

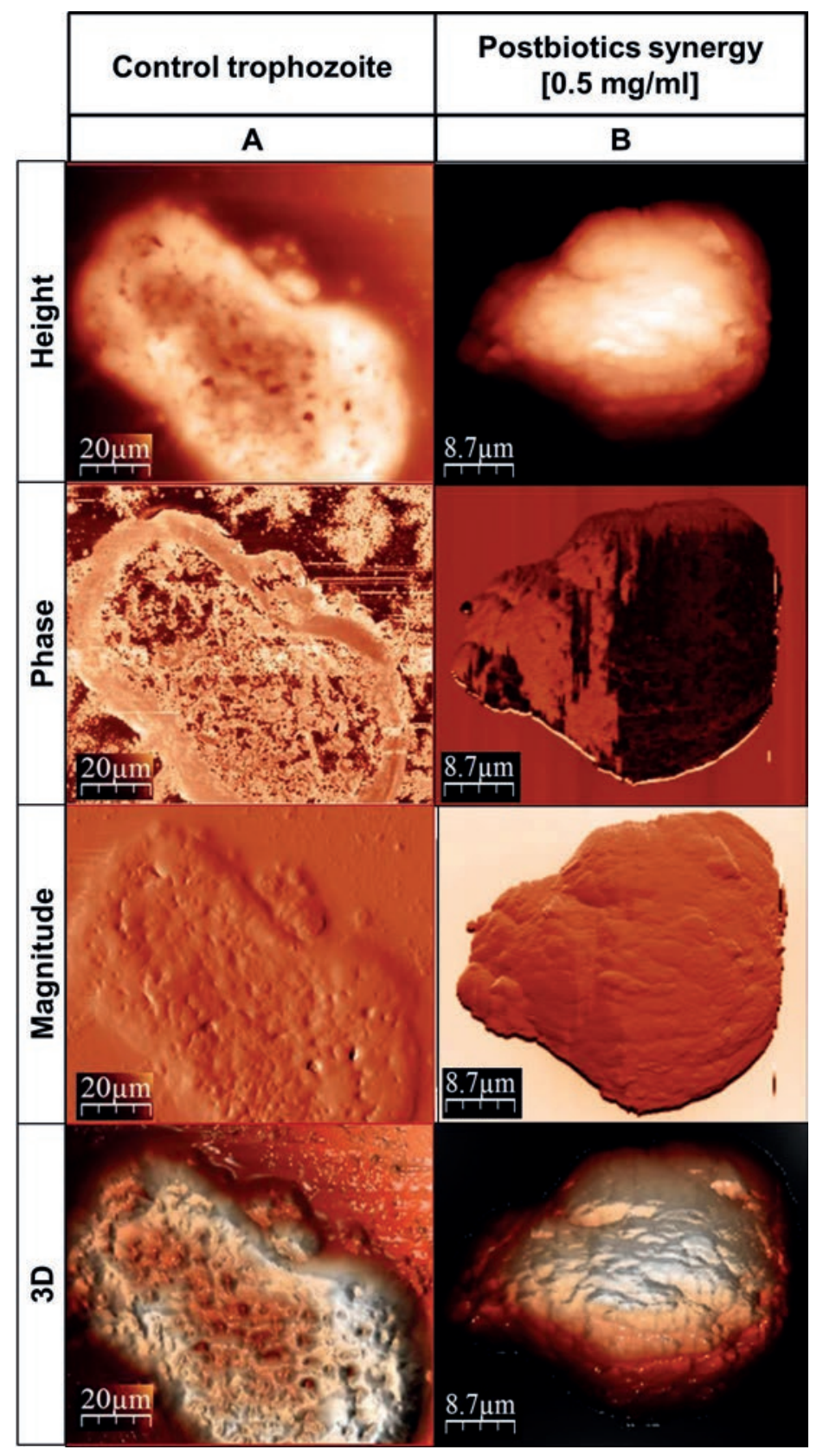

typical pleomorphic structure and a measure range of $10-60 \mu \mathrm{m}$ in control trophozoites were observed, as reported in literature ${ }^{4}$ (Column A). Furthermore, phase and magnitude images showed homogeneity in cell membrane composition, with a magnitude of $40 \mathrm{nA}$. The three-dimensional (3D) micrograph of control trophozoite showed a pleomorphic structure, maximum height of $5 \mu \mathrm{m}$ and a membrane topography with indentations and pores (Column A), while the trophozoite with treatment in the 3D micrograph presented a rounded and smaller structure and a uniform membrane with less pores (Column .B). $\stackrel{\frac{C}{ \pm}}{+}$

Table 2 shows the AFM analysis where there was an increase in roughness of $28.32 \%$ and $\mathrm{d}_{\approx}^{+}$decrease in size of $56 \%$ after postbiotic synnergy treatment at $0.5 \mathrm{mg} / \mathrm{mL}$ concentration compared to the control. 
Table 2. Morphometric analysis of Entamoeba histolytica trophozoites using software package NOVA version 1.1.0.1921 and WSxM v5.0 Develop 8.0

\begin{tabular}{llcr}
\hline E. histolytica treatment & \multicolumn{2}{c}{ Morphometric properties } & \\
\cline { 2 - 4 } & \multicolumn{1}{c}{ Morphology } & Size $(\mu \mathrm{m})$ & Roughness (nm) \\
\hline Control trophozoite & Pleomorphic structure & 74.14 & 359.5462 \\
With postbiotics synergy & Round and small structure & 32.6 & 461.3557 \\
$(0.5 \mathrm{mg} / \mathrm{mL})$ & & & -5 \\
\hline
\end{tabular}

${ }^{a}$ Mean values determined in three independent events done in triplicate.

*The data are highly significant according to the ANOVA and Tukey test.

ANOVA: Analysis of variance.

\section{DISCUSSION}

To provide a safer, non-toxic, and effective alternative to antiprotozoal drugs, recent studies have been aimed to evaluate the effect of probiotics against intestinal diseases. The WHO suggested using probiotic metabolites with microbial interference capacity to prevent pathogen intestinal colonization, producing antagonistic substances ${ }^{14}$. Many investigations have determined the inhibitory activity or microbial interference of probiotic metabolites against bacteria of medical importance. However, in few studies, this activity has been evaluated on medically important protozoa $^{18}$. A recent study ${ }^{19}$ reported in vitro coculture of $E$. invadens in the presence of $L$. casei and Enterococcus faecium. The percentage of survival reduced gradually up to $80 \%$, similar to what we found in this work. Another study using Lactobacillus fermentum and Lactobacillus delbrueckii on in vitro growth of E. histolytica reported the effective inhibiting parasite proliferation ${ }^{20}$. Some probiotic-derived components (postbiotics) such as bacteriocins have antimicrobial action on microorganisms of medical importance without toxicity to eukaryotic cells. A recent study reported the in vitro and in vivo activity of $L$. salivarius bacteriocins and supernatant on $E$. histolytica ${ }^{21}$. In the present work, we report the inhibitory activity of postbiotics on in vitro growth of E. histolytica trophozoites. Results showed that postbiotics synergy produced a higher percentage of inhibition than postbiotics separately, suggesting that Lactobacillus postbiotics could inhibit proliferation of E. histolytica trophozoites. These results support considering the use of postbiotics as a therapeutic alternative against amebiasis, additionally decreasing metronidazole consumption, due to current undesirable side effects in patients. As perspectives, we suggest to continue in vivo studies of the effect of
Lactobacillus postbiotics on E. histolytica to demonstrate whether the in vitro inhibitory activity observed in the laboratory can be reproduced in an animal model and may have a future application on disease control in patients with amebiasis. These metabolites could be considered a natural alternative, safe, and without toxicity in the future as a substitute compound for the first-choice drugs for treatment, such as metronidazole, avoiding adverse clinical effectts. On the other hand, there are few investigations on $E$. histolytica analysis by AFM. In the first reporft, our research group studied $E$. histolytica trophozoife, precyst, and cyst in situ characterization and made clear some differences (roughness, composition, elasticity, and size) between each stage ${ }^{16,22}$. In this study, the surviving cells were analyzed by AFM, and $\frac{\bar{w}}{\mathrm{c}}$ observed a decrease in cell size and a modified $€ y$ pical cell morphology using postbiotics synergy treatment. This agrees with bacteriocin properties causing cellular alterations in sensitive cells according to each bacteriocin type. This is the first report demofistrating inhibition of E. histolytica trophozoites using a synergy of Lactobacillus postbiotics, analyzing parasite membrane morphometric alterations by AFM.

In summary, postbiotic synergy derived from casei and $L$. plantarum exerts significant antiamoebiE activity on E. histolytica HM1-IMSS in vitro growth axenic conditions and induce morphometric allterations in the cell membrane of trophozoites.

\section{REFERENCES}

1. Varet H, Shaulov Y, Sismeiro O, Trebicz M, Legendre R, Coppée J, et al. Enteric bacteria boost defences against oxidative stress in Entamoeba histolytica. Sci Rep. 2018;8:9042.

2. Solaymani-Mohammadi S, Petri WA. Intestinal Invasion by Entamoeba histolytica. In: Burleigh B, Soldati-Favre D, editors. Molecular Mechanisms of Parasite Invasion. Subcell Biochemistry. NewYork: Springer; 2008. p. 221-32. 
3. World Health Organization. Amoebiasis: an Expert Consultation. Weekly Epidemiological Record. Vol. 72. Geneva: World Health Organization; 1997. p. 97-9.

4. Centers for Disease Control and Prevention. DPDx-Laboratory Identification of Parasites of Public Health Concern. Amebiasis. Available from: https://www.cdc.gov/dpdx/amebiasis/index. html. [Last accessed on 2017 Oct 30].

5. Bayoumy A, Elkeiy M, Zaalok T, Gad H, Abd Elhamid W. Coproantigen versus classical microscopy as a diagnostic tool for Entamoeba histolytica infection in the Egyptian patients. Egypt J Hosp Med. 2019;74:1423-7.

6. Adil M, Iqbal W, Adnan F, Wazir S, Khan I, Khayam MU, et al. Association of metronidazole with cancer: a potential risk factor or inconsistent deductions? Curr Drug Metab. 2018;19:902-9.

7. García C, Marchat L, López L, Ishiwara D, Rodríguez M, Orozco $\mathrm{E}$. Drug resistance mechanisms in Entamoeba histolytica, Giardia lamblia, Trichomonas vaginalis, and opportunistic anaerobic protozoa. In: Mayers D, Sobel J, Ouellette M, Kaye K, Marchaim D, editors. Antimicrobial Drug Resistance. Berlin: Springer; 2017. p. 613-28.

8. Wassmann C, Hellberg A, Tannich E, Bruchhaus I. Metronidazole resistance in the protozoan parasite Entamoeba histolytica is associated with increased expression of iron-containing superoxide dismutase and peroxiredoxin and decreased expression of ferredoxin 1 and flavin reductase. J Biol Chem. 1999;274:26051-6.

9. Ohnishi K, Sakamoto N, Kobayashi K, Iwabuchi S, NakamuraUchiyama F, Ajisawa A, et al. Subjective adverse reactions to metronidazole in patients with amebiasis. Parasitol Int. 2014; 63:698-700.

10. Patel R, DuPont HL. New approaches for bacteriotherapy: prebiotics, new-generation probiotics, and synbiotics. Clin Infect Dis. 2015;60 Suppl 2:S108-21.

11. Plaza-Diaz J, Ruiz-Ojeda FJ, Gil-Campos M, Gil A. Mechanisms of action of probiotics. Adv Nutr. 2019;10:S49-66.

12. Gao J, Li Y, Wan Y, Hu T, Liu L, Yang S, et al. A novel postbiotic from Lactobacillus rhamnosus GG with a beneficial effect on intestinal barrier function. Front Microbiol. 2019;10:477.
13. Reynés B, Palou M, Rodríguez AM, Palou A. Regulation-of adaptive thermogenesis and browning by prebiotics and postbiotics. Front Physiol. 2018;9:1908.

14. Aguilar J, Garcia R, Garcia H, Mata V, González A, Vallejo B, et al. Postbiotics: an evolving term within the functional foods field. Trends Food Sci Technol. 2018;75:105-14.

15. Aguilar-Díaz H, Díaz-Gallardo M, Laclette JP, Carrero Je. In vitro induction of Entamoeba histolytica cyst-like structures from trophozoites. PLoS Negl Trop Dis. 2010;4:e607.

16. Menchaca J, Barrón M, León A, Ortega J, Villarreal J, Hernandez J, et al. Entamoeba histolytica: trophozoite, precyst and cyst studied by atomic force microscopy. In: Mendez A, editors. Microscopy: advances in Scientific Research and Education. Mexico: Méndez; 2014. p. 153-60.

17. Diamond LS, Harlow DR, Cunnick CC. A new medium for the axenic cultivation of Entamoeba histolytica and other Entamoeba. Trans R Soc Trop Med Hyg. 1978;72:431-2.

18. Travers M, Florent I, Kohl L, Grellier P. Probiotics for the control of parasites: an overview. J Parasitol Res. 2011;2011:11.

19. Sarjapuram N, Mekala N, Singh M, Tatu U. The potential of Lactobacillus casei and Entercoccus faecium combination as a preventive probiotic against Entamoeba. Probiotics A'ntimicrob Proteins. 2017;9:142-9.

20. Shafeek Z, Ruzzuki N. The effect of different concentrations of the run and stuck bacteria (Lactobacillus fermentum, Lactobacillus delbrueckii) in trophozoite growth of Entamoeba histolytica in vitro. Int J Curr Microbiol Appl Sci. $2016 ; 5$ 924-30.

21. Mohammed S, Khalaf K, Sulaiman N. Lactobacillus salivarius bacteriocin and supernatant activity against Entamoeba histolytica in vitro and in vivo. Br J Biol Health Med Sci Res. 2015 3:19-28.

22. Ortega J, Barron M, Gracia M, Perez E, Lopez A, Meñehaca J. Biological samples observed in vitro by atomic force microscopy: morphology and elastic properties. In: Mendez A, editors. Microscopy: advances in Scientific Research and Education. Badajoz: Formatex Research Center; 2014. p. 131-40. 